Journal of Advanced Research in Applied Sciences and Engineering Technology

\title{
Bolster Barrier (BOLER) as a Guardrail Impact Device to Enhance Energy Absorbtion
}

\author{
Bibie Sara Salleh ${ }^{1,}{ }^{*}$, Asnizah Sahekhaini ${ }^{2}$ \\ Department of Civil Engineering, Politeknik Sultan Salahuddin Abdul Aziz Shah, Persiaran Usahawan Seksyen U1, 40150 Shah Alam, Selangor, \\ Malaysia \\ 2 Department of Mechanical Engineering, Politeknik Sultan Salahuddin Abdul Aziz Shah, Persiaran Usahawan Seksyen U1, 40150 Shah Alam, \\ Selangor, Malaysia
}

\section{ABSTRACT}

Guardrails are the most important road furniture which prevent vehicles from going off the road or into the opposite lane. It also protects objects at the roadside and prevent vehicles from entering into dangerous areas such a ravine or river. Performance of guardrails is not only influenced by their own design, but also the design of the vehicle. The design of guardrails is mostly aimed to reduce serious effects towards vehicles and users in an event of an accident. Bolster Barrier (BOLER) is an impact device that enhances the existing W-shape guardrails that are intended to reduce the accident impact between road users and the guardrails themselves. The application of BOLER is focused at critical areas. The purpose of this device is to reduce the numbers of serious injuries and fatalities in an accident. BOLER involved an impact test known as dolly test at MIROS Lab, Provisional CRASE Crash Centre (PC3) of Ayer Molek, Melaka. The test measured the dolly's velocity, W-beam guardrail bar's deformation and the overall force overtime trace. The results for standard the $\mathrm{W}$-beam guardrail with new impact device showed a lower peak force $(47.6 \mathrm{kN}$ versus $51.5 \mathrm{kN}$ ) and a delay in reaching peak force by 11.4 milliseconds as compared to guardrails without the new guardrail device. This delay of 11.4 milliseconds is crucial allowing airbags to inflate before full impact.

Keywords:

Guardrail; impact device; accident impact

Copyright @ 2020 PENERBIT AKADEMIA BARU - All rights reserved

\section{Introduction}

Comparatively, Malaysia has one of the best highway networks as compared with other developed countries. Nevertheless, there is still a high number of accidents involving various types of vehicles, be it private or commercial. Ministry of Transport (2015) stated that these accidents are caused by various factors, namely human, road structure, vehicles and environment $[4,5]$. According to the statistics, in 2015 , a total of 489,606 accidents were recorded, which it is about $2.8 \%$ increase as compared to 476,196 in 2014 [10]. The volume of vehicles using highways contributes to road congestions and this in turn escalates the frequency and risk of accident occurrences. Thus, road furniture such as guardrails, plays an important role in road safety particularly in terms of reducing the number of fatalities and serious injuries on highways or state roads. However, some of the serious

\footnotetext{
* Corresponding author bibie@psa.edu.my

https://doi.org/10.37934/araset.19.1.1520
} 
injury or fatal cases have been caused by guardrails themselves. The suitability of these guardrails and dividers must be reviewed to ensure the safety of road user and to minimise injuries to accident victims. Although the installation of imported rolling road safety barriers in Jalan Lapangan Terbang Subang Airport reported to have reduced road accidents by $94 \%$ within 6 month since December 2016 , the installation of such a road safety barrier is only recommended in selected locations because of the high cost. However, the existing guardrails must be regularly maintained and improved so as not to burnden the goverment finacially.

\section{Product Development}

The material used is one of the most important elements that need to be considered prior to the design process. Every part of the material properties are carefully tested and approved by the relevant professional engineers in the making of this road furniture. The primary materials consist of course sand, loose-rubber, u-clip and High Density Polyethylene (HDPE). Sand is placed inside the BOLER and it is covered by HDPE as a high impact absorber. Sand is choosen where this material is widely used as an impact absorber in most of the sharp corners in a high speed track circuit as a high impact absorption measure. According to geologists, sand particles range from $0.0625 \mathrm{~mm}$ (or $1 / 16 \mathrm{~mm}$ ) to $2 \mathrm{~mm}$ in diameter [2]. Loose-rubber also been used where the pure rubber that has been grinded and bound with the binder. This rubber is located between the BOLER and w-beam guardrail, is moulded according to the shape of the $w$-beam guardrail. Eight holes are drilled through the $w$-beam guardrail and the loose-rubber is fitted using bolts and nuts. The space between the rubber acts as an impact absorber which reduces the risk for vehicles to bounce back to the road when a collision occurs. The use of loose-rubber can also protect the shape of the w-beam guardrail as the energy from a high impact is absorbed, leading to a reduction in the maintenance of the $w$ beam guardrail.

The next material is $\mathrm{U}$-clip. The high level of oxidation resistance in air at the ambient temperature is normally achieved with the addition of a minimum of $13 \%$ (by weight) chromium, where up to $26 \%$ is used for harsh environments [8]. U-clip is used to attach the BOLER to the wbeam guardrail as a strong holder when the impact between a vehicle and the w-beam guardrail occurs. Four holes are drilled through the guardrail and they are tightened by bolt. Each one-meter BOLER consists of two U-clip and four bolt. The U-clip is made of stainless steel that is highly recommended by some experts because of it durability in any type of weather and high impact conditions as well as for its long lasting feature and its $100 \mathrm{~mm}$ size in accordance to the size of HDPE.

HDPE is known for its large strength-to-density ratio. The density of HDPE can range from 0.93 to $0.97 \mathrm{~g} / \mathrm{cm} 3$ or $970 \mathrm{~kg} / \mathrm{m} 3$. HDPE, high density polyethylene is one of the most important materials in BOLER and it is highly recommended by some of the experts because HDPE is already widely used in the industry of road furniture, especially in Spain. In fact, the w-beam guardrail in Spain is made of HDPE; moreover, HDPE is used in the underground oil transportation pipe in the current oil rigs. It is round and has a diameter of $100 \mathrm{~mm}$. Figure 1 shows the graphic sketch of BOLER.
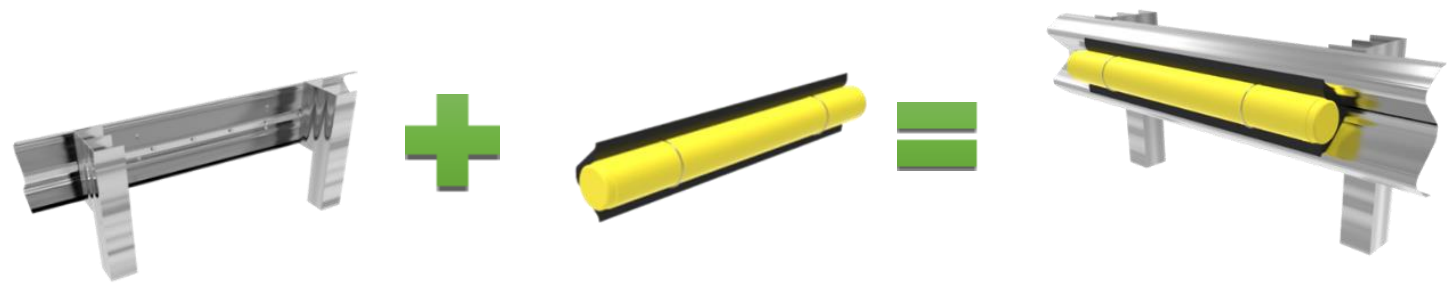

Fig. 1. Application of Bolster Barrier at Existing W-beam Guardrails. 


\section{Methodology}

This research was carried out in a few main stages :

\section{Stage 1 : Knowledge Acquisition}

This stage involves the process of getting data from past research on high impact tests as well as interviewing a few experts of the field.

\section{Stage 2 : Design Process}

The process of design process include the study of industry needs, customer requirements, product specifications and concept evaluation.

Stage 3 : Product Development

After design, component and materials have been identified, the fabrication of the product stage will focus on the simulation framework.

\section{Stage 4 : Evaluation}

Complete prototype was tested using crash tests and the performance have been evaluated. Next, the prototype will undergo simulation process using Finite Element Method (FEM). If it fails, the modification and test run will repeat until it is successful. The framework of simulation of the structure using Finite Element Method (FEM) as below:

\section{Table 1}

The framework of simulation of the structure using Finite Element Method (FEM)

\begin{tabular}{|c|c|c|c|}
\hline Speed & & $80 \mathrm{k}$ & \\
\hline Angle of Impact & $5^{\circ}$ & $15^{\circ}$ & $25^{\circ}$ \\
\hline Existing Guardrail & & & \\
\hline $\begin{array}{l}\text { Redesigned existing } \\
\text { guardrail }\end{array}$ & To be studied & To be studied & To be studied \\
\hline Speed & & $110 \mathrm{~K}$ & \\
\hline Angle of Impact & 5 & 10 & 25 \\
\hline Existing Guardrail & & & \\
\hline $\begin{array}{l}\text { Redesigned existing } \\
\text { guardrail }\end{array}$ & To be studied & To be studied & To be studied \\
\hline
\end{tabular}

The structure will be analysed using Finite Element Method (FEM) through Finite Element software MSC PATRAN dand MSC NASTRAN as FEM solver. The testing will be down at Intelligent Dynamic \& System (IDS) Malaysia Japan International Institute of Technology (MJIIT), UTM, Kuala Lumpur. 


\section{Results}

The small scale impact test was done in the first stage of the research on 24th November, 2016 at the Malaysian Institute of Road Safety Research Provisional CRASE Crash Centre Laboratory (MIROS PC3) Melaka. The impact tests were performed to replicate the frontal Dolly impact test scenario, but in a small scale and condition according to the customer-specified test method. The tests utilized the equipment and the services available at MIROS PC3 facilities to suit the test method requirements. In addition, this report describes the methodology and activities performed as well as highlighting the test results.

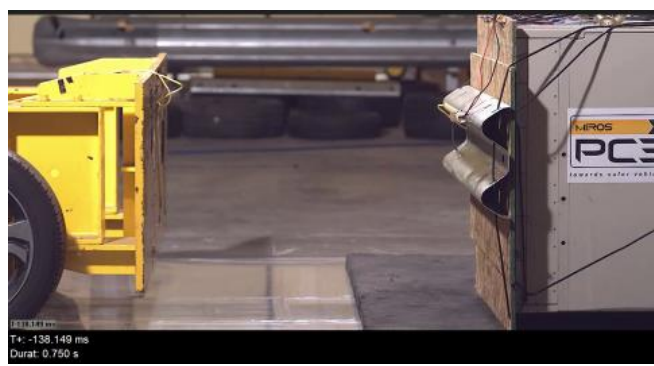

Fig. 2. Standard W-Shape Guardrail

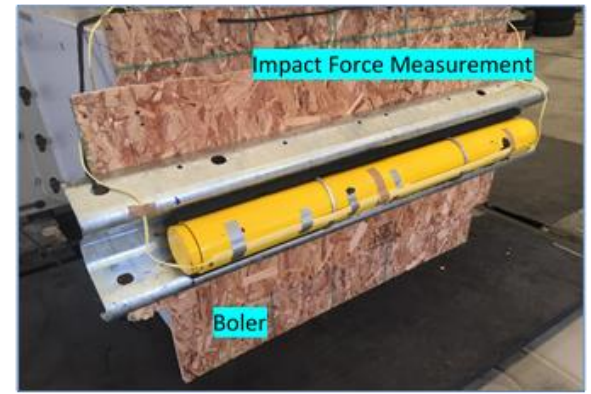

Fig. 5. The specimen was mounted on the rigid offset barrier block

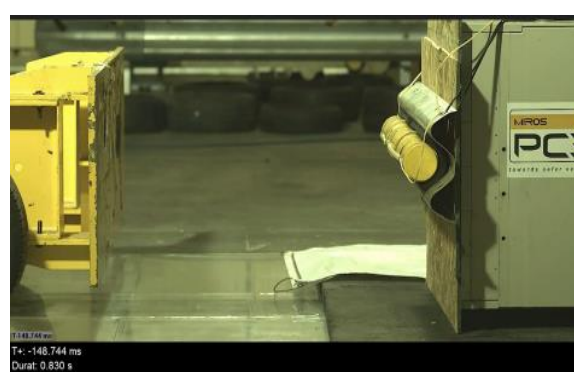

Fig. 3. New Impact Guardrail Device

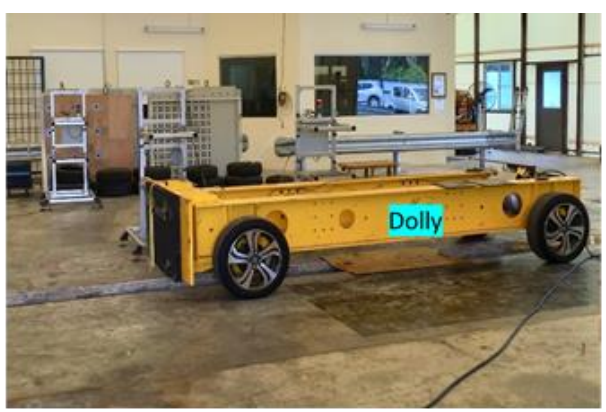

Fig. 6. Movable Dolly with mass of $1212 \mathrm{~kg}$

The impact tests carried out measured the Dolly's acceleration and W-beam guardrail bars' displacement. Based on the results, the new impact device with standard W-beam showed different performance when impacted. It showed lower peak force and delayed peak force by 11.4 milliseconds. These results show that the delay in collision impact which helps to increase the inflation of airbag by $62 \%$. 


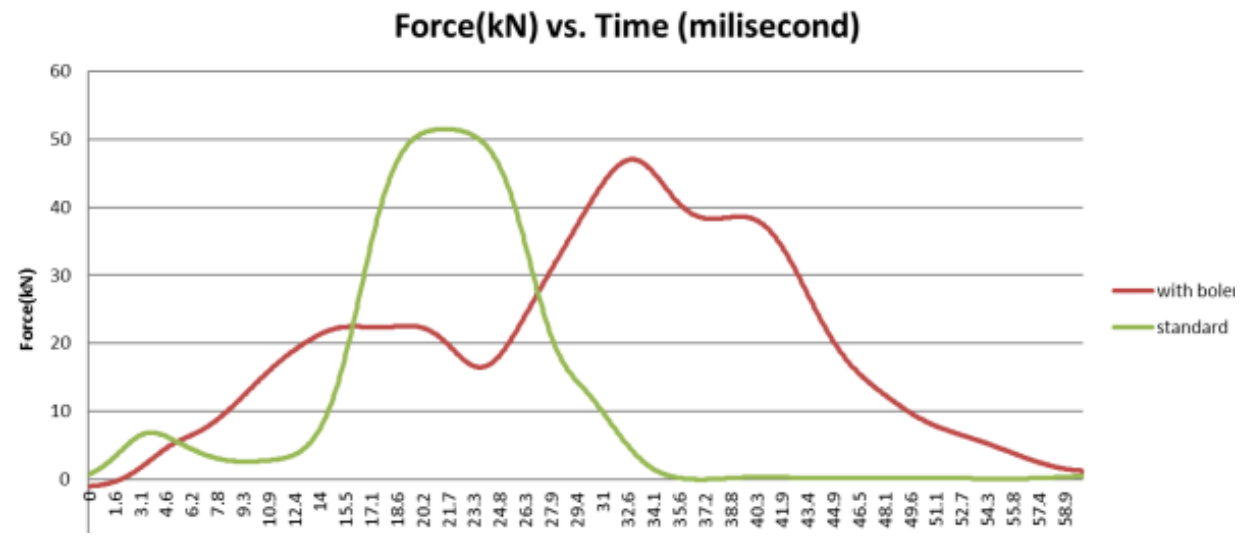

Fig. 7. The performance of force versus time

From the result obtained from MIROS, the data can be summarized that the maximum peak force time which occurred for the Standard W-beam guardrail is 21.4 milliseconds and for the BOLER is 32.8 milliseconds. This indicated the delayed time at peak force between the two specimens by 11.4 milliseconds. It can be concluded hence that the BOLER can delay the impact time of a crash by $34.76 \%$. The data also shown that the maximum impact force for the Standard W-beam guardrail was $51.52 \mathrm{kN}$ and for the BOLER, it was $47.06 \mathrm{kN}$. This showed a reduction of force by $4.46 \mathrm{kN}$. This proves the improved force absorption capability of the BOLER as compared to the Standard W-beam guardrail.The inflation deployment of airbag is an important element in saving lives. The full inflation of airbag will occur within 30 milliseconds [13]. Thus, the BOLER's delayed peak force which was 11.4 milliseconds can help to add to airbag's full inflation time before the maximum peak force by $62 \%$.

\section{Conclusion}

In conclusion, it can be concluded that the existence of BOLER can help to boost the safety of road users by reducing the risk of severe accidents or fatalities. The descriptions of the product in this research in terms of the material used, its shape and the results of the usability test clearly revealed the significant advantage of this new innovative product.

The research's preliminary tasks up to the summarized results indicate that the BOLER will provide a positive contribution for the society in terms of the safety aspect of the daily users of the transportation system. It is hereby declared that the results of this paper represents the data obtained and stands of the authors. Lastly, all the test results presented were actual recordings to prove the real workability of the product.

\section{Acknowledgement}

The authors would like to thank the Polytechnic of Sultan Salahuddin Abdul Aziz Shah for supporting this research and the Ministry of Higher Education of Malaysia for sponsoring this research under Mylnovasi 2016. We are also thankful to the Malaysian Institute of Road Safety Research (MIROS), practitioners and consultants for providing comprehensive and important information during the data acquisition process.

\section{References}

[1] Akat, R. A. (2016). Statistics of peak of an accident to happens.

[2] Argiculture Canada. (1976). Glossary of Terms In Soil Scince. Canada: Canada Department of Argiculture.

[3] Bhatia, A. (2016, May 9). Why, How, and When to Utilize Usability Testing. Retrieved from Shopify Inc: 
https://www.shopify.com/partners/blog/108023878-why-how-and-when-to-utilize-usability-testing

[4] Borneo Post. (2011, August 30). Various factors that contributes to an accident. Borneo: Borneo Post.

[5] Contributing factors in accidents. Malaysia: Ministry of Transport Malaysia (2015). Retrieved from Ministry of Transport Malaysia: http://www.mot.gov.my/en

[6] Gabler, Hampton Clay, Douglas J. Gabauer, and W. Lad Szalaj. Safety audit of fatalities and injuries involving guide rail. No. FHWA-NJ-2007-001. New Jersey Department of Transportation, 2006.

[7] Harian, B. (2009, April). Express bus passengers killed in an accident at KM 433 of North-South Highway. Berita Harian.

[8] ISSF. (2012). The Stainless Steel Family. Retrieved from http://www.worldstainless.org/ Files/issf/ non-imagefiles/PDF/TheStainlessSteelFamily.pdf

[9] LEVEL. (2016, September 12). The authority on sustainable building. Retrieved from LEVEL: http://www.level.org.nz/water/water-supply/system-layout-and-pipework/pipe-materials/

[10] Mat, A. C. (2016). Statistic of accidents happens in Malaysia in Year 2014 and 2015.

[11] Mohd Syazwan Solah, Azhar Hamzah, Noor Farahdilla Paiman. (2016). Final report for Technical Service for Customized Impact Testing of W-beam Guardrails. Kajang: MIROS.

[12] National Highway Traffic Safty Administration. (2008). National Motor Vehicle Crash Causation Survey. Virgina: U.S. Department of Transportation, National Highway Traffic Safty Administration.

[13] Nordhoff, L. S. (2005). Chapter 16: Frontal Crashes: Biomchanics and Injuries. In Motor Vehicle Collision Injuries (p. 422). California: Jones and Bartlett.

[14] PROTEX KARTING. (2015). PROTEX KARTING. Retrieved from PROTEX KARTING: http://www.protexkarting.com/technical-specifications/

[15] Yang, D. M. (n.d.). Rubber and Others Latex Product. Retrieved from http://www.faculty.ucr.edu/ legneref/botany/rubber.htm 